and thoughtfulness. There are 375 references (many carefully annotated) and 22 case histories to highlight various ethical dilemmas.

Of course, like everything else, the more the subject is studied, the more difficult and complex it becomes. Attempting to classify different kinds of paternalism, Childress suggests that paternalism may be hard or soft, active or passive, pure or impure, restricted or extended, direct or indirect, and so on, until we are in danger of getting bogged down in sterile analysis and endless escape clauses designed to allow for occasional (or not so occasional) exceptions to general ethical principles.

The subject is difficult, emotive and replete with opportunities for misunderstanding - due partly to semantic difficulties. Even so, it is not easy to see exactly where Professor Childress stands with regard to paternalism, nor when he is content whisper it softly - to leave matters to the discretion of the individual doctor. In the final sentence of his preface, for example, he states 'Our acts, policies and practices in health care should express care and concern on the one hand, and respect for persons on the other - in short, limited or constrained paternalism'. Amen to that. Would that all our critics held the same enlightened view. Yet at times you get the feeling he is taking quite a different view. For example, 'Nowhere is paternalism more rampant than in the care of patients who are terminally ill or dying'. And when discussing how 'paternalism' is to be defined, he insists on including in his definition, 'a refusal to acquiesce in a person's wishes, choices or actions . . . This puzzles me. Try as I might, after reading the whole book carefully I was still unable to understand why this alarming idea of going against the patient's wishes should be included in the definition of something that he approves of, provided it is 'limited or constrained'. How limited? How constrained? It seems that when the chips are down, we are still stuck with our old friends, compassion, compromise and common sense.

THURSTAN B BREWIN Institute of Radiotherapeutics and Oncology, Glasgow.

\section{Medicine, Morals and the Law}

Sheila McLean and Gerry Maher. England, Gower, 1983. £12.50, hardback
It is a promising idea for a medical person and a legal person, both interested in moral issues, to get together and produce a collection of joint essays on morals, ethics, medical science, law and practice. Medico-legal matters ought wherever possible to be dealt with in such an interdisciplinary manner.

The authors examine many contemporary issues, and offer a number of opinions and conclusions. When does life begin, they ask, at fertilisation, at implantation, or when? Is it satisfactory that in abortion neither the mother nor the child nor the father appear to have any legal 'rights'? Euthanasia (in so far as it takes place) and switching off the life support machine are matters best left to the decision of the individual doctor, the authors believe and should not be regulated by law. In view of the desirability of autonomy and of the choice inhering in the patient, as a dignified human being, he should always be informed of the facts of his situation, they maintain. And experimentation is necessary for medical advance, but should be limited by the principle of utilitarianism. The authors believe sterilisation and contraception should be a matter for the individual, who should be entitled to control his or her capacity for reproduction. The answer to the flood of negligence actions is to seek to improve mutual patient-doctor trust. Patients expect too much; the standard imposed by the law upon doctors is too low. And, the authors conclude, decision-taking in medicine relies too heavily upon technical remedies rather than preventive medicine.

This book is interesting, readable, quite well documented, and seeks to propound theoretical and viable principles for resolving medico-legal problems, principally those of a moral or ethical character. The 'solutions' offered are not terribly consistent nor profound. They sometimes give the impression of compromise, and they sometimes seek to evade the moral and ethical issues. But they undoubtedly make a contribution to knowledge and thinking and understanding.

The text is a modern typescript reproduction, with unjustified pages, not a bad production of its kind, but not comparable to the printed page.

ALEC SAMUELS

Faculty of Law, University of Southampton.

\section{Law and Ethics in the Medical Office}

Marcia A Lewis and Carol D Warden. Philadelphia, F A Davis Co, 1983. $£ 11.20$ paperback.

Some books from the United States require translation; this book requires translocation. The form and content of this manual would make it very useful for medical secretaries and receptionists if only it dealt with the topics as they might apply to medical practice in the United Kingdom.

The book is divided, perhaps arbitrarily, into two equal sections: one dealing with the law, the other with ethics. In the medical office the legal implications of employment and bookkeeping are as important as the medicolegal aspects of consent, confidentiality and litigation. The section on ethics, as we might expect, covers the history of ethical codes and discusses the features and constraints when considering action in abortion, sterilisation and euthanasia. The form is attractive. I admit to a liking for statements of learning objectives and each chapter of this book opens with a summary of the knowledge which should be absorbed by the reader on completing the chapter. The function of this book as a teaching aid and instruction manual is enhanced by the discussion questions posed at the end of each chapter.

Both the legal and ethical sections can be adversely criticised. Although some aspects of the two sections are common to medical practice on both sides of the Atlantic, the differences become distracting. The details given about fee collecting are irrelevant and, of course, the names of the posts and duties in the US medical office are strange to us. However, I commend the form and layout used in this book, the clear definitions of various terms in law and ethics and the easy access to references within the text as well as for further reading.

The experience of one of the writers as a patient seems to have initiated this publication and may explain the proper preaching it contains to all medical office staff of the need for real caring as well as sensitivity to patients' feelings. References are made to the American Association of Medical Assistants and I know the Association of Medical Secretaries in the United Kingdom has an established link with this organisation. Although this US publication will be of little use to the staffs in health centres and hospitals in 